\title{
Reoquafia
} Malaysian Tournal of Society and Space

\section{Perception of the local community toward the yellow-crested cockatoo (Cacatua sulphurea abbotti), a critically endangered species in Masakambing Island, Indonesia}

\author{
Ihsannudin $^{1}$, Kliwon Hidayat ${ }^{2}$, Keppi Sukesi ${ }^{3}$ Yayuk Yuliati $^{4}$ \\ ${ }^{1}$ University of Trunojoyo Madura, Bangkalan, Indonesia \\ ${ }^{2,3,4}$ Brawijaya University, Malang, Indonesia
}

Correspondence: Ihsannudin (email: ihsannudin@trunojoyo.ac.id)

Received: 27 December 2019; Accepted: 06 August 2020; Published: 29 November 2020

\begin{abstract}
The yellow-crested cockatoo is an endangered species with habitat is in a non-conservation area with community ownership. The local community's action is determined by perception related to the information about this animal. The study aimed to find out the perception of the local community of Masakambing Island to the yellow-crested cockatoo based on community structure and the advantages-disadvantages aspect. The study was conducted in Masakambing Island, Masalembu sub-district, Sumenep Regency, East Java Province, Indonesia. Quantitative and qualitative data were obtained from observations, closed interviews with the 160 respondents and open interviews with the key informants (local figures, government and non-government elements) and Focus Group Discussion (FGD). This study used mixed methods with convergent parallel mixed-methods design. The results showed that the community structure is a fatalist one with a nature capricious perception. The community has limited life choices and is controlled by other powers. Unsurprisingly, the local community does not have a vision or carry out any real action to conserve this animal. Meanwhile, the community has a perception that the yellowcrested cockatoo has more advantages than disadvantages. The implication is that added-benefits of alternative livelihood for the community based on yellow-crested cockatoo are required. Then, all of the community members can access the benefits of resources, especially based on the existence of the yellow-crested cockatoo.
\end{abstract}

Keywords: perception, cockatoo, community, masakambing, structure, livelihood

\section{Introduction}

The IUCN Red List of Threatened Species has categorized the yellow-crested cockatoo (Caccatua sulphurea abbotti) as critically endangered status. Likewise, the Indonesian government regulation No.7 / 1999 concerning Preservation of Plant and Animal categorized this 
animal as protected species. The yellow-crested cockatoo is an endemic of Masakambing Island, Sumenep Regency, East Java Province, Indonesia and currently, population is 22 (Nandika et al., 2019).

Population decline of critical species is generally caused by agricultural expansion, overexploitation, urbanization, industrialization, pollution, fire, presence of other species (exotic species), genetically modified organisms (GMO), climate change, illegal trade, changes in habitat, limited habitat range, habitat fragmentation and degradation (Castelletta, 2005; Zegeye, 2016). In case of the yellow-crested cockatoo in Masakambing, it is more due to hunting and decreasing of carrying capacity related to human activities (Nandika et al., 2012a; The IUCN red List of Threatened Species, 2017).

Study of the yellow-crested cockatoo is interesting because the animal habitat is located in a community ownership area. Such areas usually deal with conflict of interests because of similar resources are being used for different purposes between animal and community (Rolling \& Jiggins, 1997; Rist et al., 2006).

When animal coexists with the community, structure and function of the community in the environment affects actions. Community action as a social system of ecosystems starts from information receiving and then through its perception will be interpreted as a decision to take action (Marten, 2011). Perception implies a sense of the complexity of community conditions, images and stories that exist in thinking.

Some experts have examined community perceptions based on community structure and culture. Douglas (1970) suggested perception is egocentric. Furthermore, perception of nature is greatly influenced by the structure and form of community solidarity (Thompson, 1997). However, perception is dynamic and differs from one community to another. Theoretically, a community with an individualist structure will have a 'nature benign' perception (Gyawali \& Dixit, 2001). In one case, the farming community in Naivasha Kenya tends to have a nature tolerant perception (Billgren \& Holmen, 2008).

In the context of the yellow-crested cockatoo that coexists with the community and has a potential conflict for a natural resource use, attention just on community structure is not enough. Understanding of possible interaction and conflict between humans and animals is required (Twyman, 2001). Reflecting on Jaguar conservation activities in Brazil, most of the community has a social perception rather than economic, it becomes the key for determining conservation strategies (Bredin et al., 2015). Likewise, in conservation activities in Namibia, men and women have different perceptions of wildlife, when conservation activities are framed from men's perceptions it turns out to reduce women's participation (Gore \& Kahler, 2012).

It means, perception is specific, which results in particular policies and actions (de Snoo et al., 2013; Bennett et al., 2017). Study of perception is useful for determining conservation strategies, increasing community participation in conservation and correction of failure (Sainsbury et al., 2015; Thaman et al., 2016). Some explanations show the importance of community perception of animals in conservation activity, including in the conservation of the yellow-crested cockatoo in Masakambing Island. 


\section{Literature review}

\section{The yellow-crested cockatoo as endangered species}

The yellow-crested cockatoo or Cacatua sulphurea (C.s) is an Indonesian endemic animal that has six sub-species including C.s. sulphurea, C.s. abbotti, C.s. djampeana, C.s. occidentalis, C.s. parvula, and C.s. citrinocristata (Rowley et al., 2018). It was stated by Prijono (2008) that, although C.s Abbotti or the yellow-crested cockatoo is tolerant of landscape changes due to human activities but it was identified as nearly extinct. It is not surprising, the IUCN placed this animal on status of the red List of Threatened Species in the critically endangered category (Trainor, 2002; IUCN, 2017). In the national scope, Indonesian Government Regulation No.7/1999 concerning Preservation of Plant and Animal Species also define this animal as a protected animal. The regulation states animals are classified as protected when they have a small population, and a fast decline in the number of individuals in the wild and limited distribution area (endemic).

Morphologically, this animal has a bill length of $33 \mathrm{~mm}$, crest $117 \mathrm{~mm}, 15.5 \mathrm{~mm}$, earpatch, $260 \mathrm{~mm}$, wing $146 \mathrm{~mm}$ (Collar \& Marsden, 2014). This animal starts its activity in the morning between 04.45 - 05.30 AM to find food, mate and other activities, and ends at 05.00 05.45 AM to sleep in groups (Nandika et al, 2019). The habitat is in plantations and community settlements by using several types of trees for food and nest including kapok randu, coconut, breadfruit, tamarind and mangrove (Avicennia sp) (Nandika, et al, 2012b).

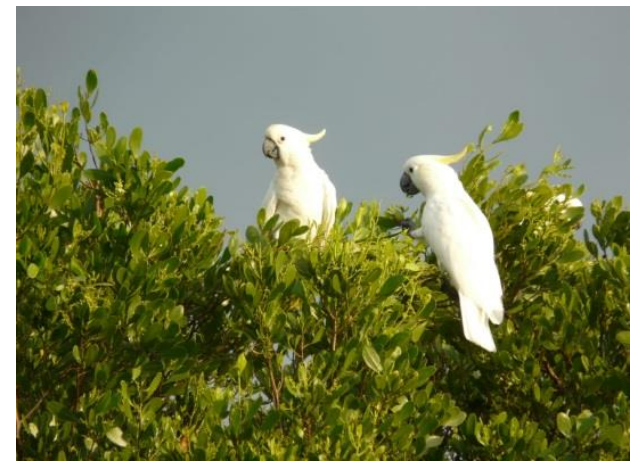

Source: Primary Data, 2018

Figure 1. The Yellow-Crested Cockatoo (C.s abbotti) in Masakambing Island

\section{Community perception}

The study of community perception of nature, including the yellow-crested cockatoo, is needed to determine the interrelation between the community and its environment that affects the decision process. Marten (2011) states the perception of information is the basis of decision making process in a community system in taking action on ecosystems. 


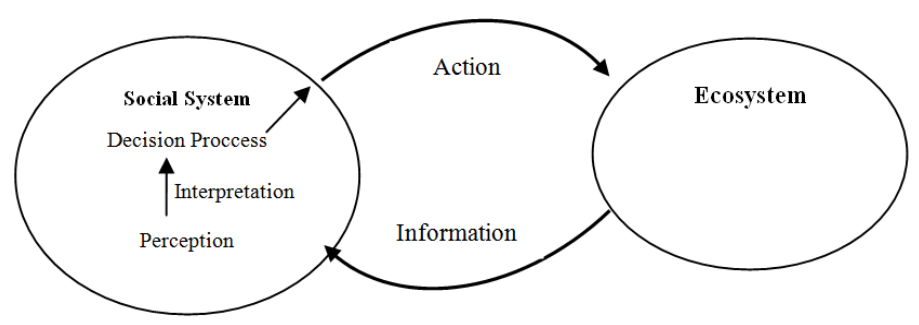

Source: Marten, 2011

Figure 2. Community's perceptions of ecosystem management decisions

Furthermore, community perception on ecosystem is generally divided into (a) nature is connected, people perceive all events both directly and indirectly as a consequence of human action; (b) nature is benign, nature provides the services that humans want as long as humans do not radically change the natural conditions of the ecosystem; (c) nature is fragile, nature has a soft balance that will collapse if humans change the natural conditions of the ecosystem; (d) nature is durable, people can use and manipulate nature as desired; (e) nature is capricious, there is an emphasis on random elements in the ecosystem (for example a farmer depends on nature so feels nature is very varied and unpredictable, sometimes supporting the crop production but sometimes damaging it) (Marten, 2011).

Community perception can be elaborated based on the condition of the community structure through the theory of social-culture viability developed by Douglas (1970). He stated that the social dimension expressed as "grid" (differences in role and stratification limit individual behavior) and "group" (how social units limit individual thought and action). Some experts continue to develop this theory by defining social structure/relation by dividing it into individualist, fatalist, hierarchy and egalitarian types (Douglas \& Wildavsky, 1982; Thompson et al., 1990). Each of these types produces a different type of nature perception (view of nature). Steg and Sievers (2000) have synthesized these: fatalist has nature capricious perception, hierarchists has nature tolerant perceptions, individualist has benign nature perception and egalitarian has ephemeral nature perception (Figure 3).

Billgren and Holmen (2008) explained the categories of (a) fatalists, community has limitation in life choices, dependent and influenced by external forces; (b) hierarchists: community's life is controlled by a group or higher external (social) rules; (c) egalitarians: community has strong ethical principles and ensures everyone get their resources; (d) individualists: community can control their own lives and able to control others both inside/ outside the group; (e) autonomous: a small number of people, decide to live outside of other communities and do not want to control or to be controlled by others. While, perceptions of nature (myths of nature) are explained: (a) nature capricious, consider the nature as strange and always changing, then nature management and vision are not required because they are not useful; (b) nature tolerant: assume nature is resilient and able to resolve everything that happens; if there is disruption, the community knows how to manage the problems; (c) nature ephemeral: considers the nature should be managed carefully because the nature cannot forgive, meanwhile human manipulation efforts may cause disaster any time; (d) nature benign: assuming nature is "forgiving" and can recover from all the changes that occur, so the management is ordinary. 

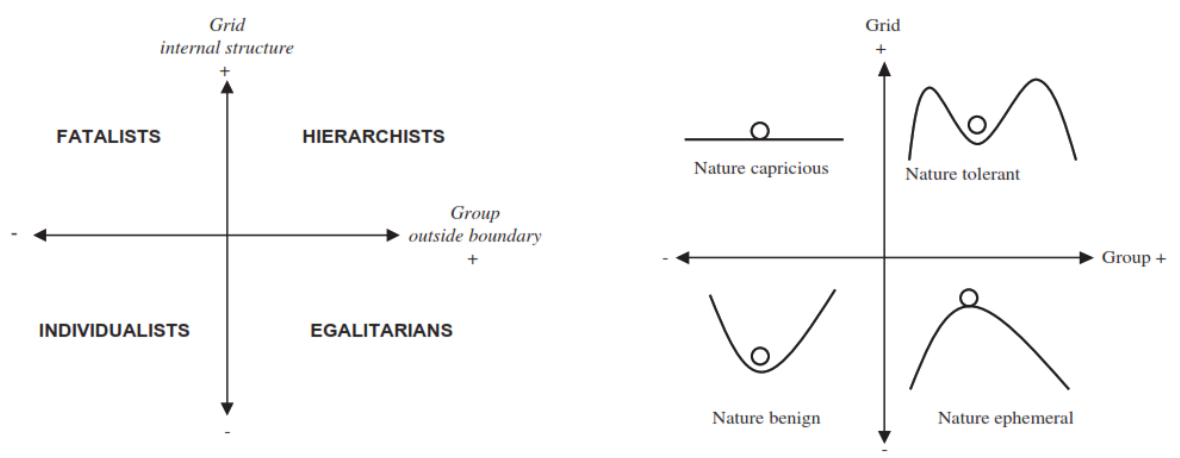

Source: Steg \& Sievers, 2000

Figure 3. Relationship between community structure and perception

Relationship conditions are absolutely dynamic depending on social, economic, biophysical and legal political factors (Abdullah et al., 2013; Riveraa et al., 2017). Likewise, the elements of gender and age influence perception (Daltona, 2014; Jaafar et al., 2015; Kanagavel, et al., 2016). On the other hand, value, prejudice and characteristic of animals also influence perception (Thompson \& Mintzes, 2002; Lestera et al., 2017). Thus, different community and natural objects (such as animals and plants) produce different perceptions.

To support the study of community perceptions based on the structure needs to investigate the relationship complexity regarding aspects of advantages or disadvantages (conflict) between nature (animal or plant) and humans (Twyman, 2001; Novelli et al., 2006). If the animal is perceived as a source of fear, human lead to decline in population. (Bencin, 2016). On the other hand, animal and plant can be seen as a consumptive, tourism, social-economic or environmental advantages (Wearing \& Neil, 1999).

However, animal or plant can be perceived as both advantages and disadvantages at once. Reflecting on finding of Taruvinga and Mushunje (2014), the elephant in Africa is considered as the animal that damage the crops and predatory, but also has a potential source of income. Consequently, it is necessary to make the community do not spread negative prejudice over the nature of the animal's ferocity (Friedrich et al., 2014).

\section{Method and study area}

This study used mixed-method with convergent parallel mixed-method design. The reason is interpretation becomes comprehensive, where quantitative and qualitative findings will mutually confirm and/or complement each other (Clark \& Creswell, 2015).

The study location was purposively chosen in Masakambing Island village (Ketapang sub-village and Tanjung sub-village), Masalembu sub-district, Sumenep Regency, East Java Province during 2018, October- 2019, February. This location has been main consideration because the Island with $7.79 \mathrm{Km}^{2}$ area and 1,365 population is an endemic habitat of the yellowcrested cockatoo (C.s abotti).

Primary and secondary data were used in this research. Primary data were obtained from field observations in Masakambing Island and interviews (close-ended and open-ended). Closeended interviews using questionnaires with the 160 respondents of local community who were selected using the proportionate random sampling method (83 respondents from Tanjung subvillage and 77 respondents from Ketapang sub-village). As results, quantitative data were 
obtained that related to community structure (livelihood type, income and norm adherence). Furthermore, this data analyzed by descriptive frequency analysis.

Open-ended interview was conducted with key informants consisting of local community figures related to education, women, youth and religious; government elements such as village government, Natural Resources Conservation Agency of East Java, Indonesia (NRCA); NGO elements such as KKI-IPP (Konservasi Kakatua Indonesian-Indonesian Parrot Project) and PA Kawali as conservation volunteer. Focus Group Discussion (FGD) was conducted by presenting representative of the local community of Masakambing Island, elements of government and nongovernment. This data are related to the local community perception towards the yellow-crested cockatoo.Then, the community structure will be related with perception toward the yellowcrested cockatoo by the concept of Billgren and Holmen (2008).

Table 1. Syntesis of relationship between community structure and perception

\begin{tabular}{ll}
\hline \multicolumn{1}{c}{ Community structure } & \multicolumn{1}{c}{ Perception } \\
\hline $\begin{array}{l}\text { Fatalist: the community has a limitation in life } \\
\text { choice, dependent and influenced by an external } \\
\text { power. }\end{array}$ & $\begin{array}{l}\text { Nature capricious: community considers nature as } \\
\text { strange and always changed, then vision and nature } \\
\text { management are not required because they are } \\
\text { unuseful. } \\
\text { Nature tolerant: community assumes nature is resilient } \\
\text { and able to resolve everything that happens. If there is } \\
\text { disuption, the community knows how to manage the } \\
\text { Hierarchist: community's life is controlled by a group } \\
\text { or higher external (social) rule. }\end{array}$ \\
$\begin{array}{l}\text { Egalitarian: the community has a strong ethical } \\
\text { principle and ensure everyone gets the resources. }\end{array}$ & $\begin{array}{l}\text { Nature ephemeral: community considers to manage } \\
\text { nature carefully because nature cannot forgive, and } \\
\text { human manipulation may cause disaster any time. }\end{array}$ \\
$\begin{array}{l}\text { Individualist: community can control their lives and } \\
\text { able to control the others, both inside/outside the } \\
\text { group }\end{array}$ & $\begin{array}{l}\text { Nature benign: community assumes nature is } \\
\text { "forgiving" and can recover from all the changes that } \\
\text { occurred, so the management is ordinary. }\end{array}$ \\
\hline
\end{tabular}

Source: Billgren \& Holmen, 2008

Perception study is complemented by connecting local community perceptions about the advantages and disadvantages aspect of yellow-crested cockatoos. This study uses the concept as stated by Taruvinga \& Mushunje (2014) as presented in the following table.

Table 2. Items of perception based on advantages and disadvantages aspect

\begin{tabular}{ll}
\hline \multicolumn{1}{c}{ Advantages } & \multicolumn{1}{c}{ Disadvantages } \\
\hline $\begin{array}{l}\text { Existence of yellow-crested cockatoo is natural. } \\
\begin{array}{l}\text { Provide income benefits such as tourism activities } \\
\text { The trigger of infrastructure development (road, } \\
\text { communication, transportation, electric, etc.) }\end{array}\end{array}$ & $\begin{array}{l}\text { Damaging crops } \\
\text { Spending the time (community keep the crops) } \\
\text { Required for culture or ritual }\end{array}$ \\
$\begin{array}{l}\text { Leducing/occupying land for the future generation, } \\
\text { Serving food, medicine or entertainment }\end{array}$ & $\begin{array}{l}\text { crop cultivation and spring. } \\
\text { Social instability (community fear) }\end{array}$ \\
\hline
\end{tabular}
Source: Taruvingan \& Mashunje, 2014

As result, qualitative data were obtained and analyzed by examining and interpreting non-numerical observations to find meaning and patterns of relationships. The qualitative data analysis uses the bottom-up approach (Clark \& Craswell, 2015). Meanwhile, secondary data are 
used to complete primary data, consists of documentation and reports obtained from the Masakambing Island Village Government, NRCA and KKI-IPP.

\section{Results and discussion}

\section{Community structure and perception about the yellow-crested cockatoo}

The perception of local community to the yellow-crested cockatoo is very important to be studied because it illustrates the sense and description of thoughts. In addition, the study will provide an explanation of the structure and the relationship of the community to this animal. The social system of the community has obtained information from the ecosystem related to the yellow-crested cockatoo. Furthermore, the information was interpreted by using the social system in this community as a decision for action related to the yellow-crested cockatoo.

Theoretically, the local community with fatalist structure is characterized by limited life choice and dependent/influenced by external power (Thompson. 1997; Billgren \& Holme, 2008). The findings showed Masakambing Island community included as fatalist structure due to limitations of life choices and the dependent/influenced by external factors (village government).

Limited life choice is indicated by dominance of livelihoods that are limited to the agriculture sector (40.6\%). Ironically, this sector has not been able to provide welfare because many poor people work in this sector. Poor-non poor category is used to indicate rural community poverty line by Indonesian Statistic Bureau. The poor category for those who has income less than 136.08 USD per month and non-poor by above 136.08 USD per month. Indeed, agriculture commodities in Masakambing Island have a very low price. For example, kepok banana sold at 0.5 USD per-bunch.

Table 3. Analysis of income categories and types of work

\begin{tabular}{lccc}
\hline \multirow{2}{*}{ Types of work } & \multicolumn{2}{c}{ Income categories } & Total percentage \\
\cline { 2 - 4 } & \multicolumn{1}{c}{ Poor } & \multicolumn{1}{c}{ Non-poor } & \\
\hline Farmer & $44,6 \%$ & $14,3 \%$ & $40,6 \%$ \\
Fishermen & $15,2 \%$ & $21,4 \%$ & $16,0 \%$ \\
Trader & $15,2 \%$ & $21,4 \%$ & $16,0 \%$ \\
Craftmen/ & $6,5 \%$ & $7,1 \%$ & $6,6 \%$ \\
services & $8,7 \%$ & $28,6 \%$ & $11,3 \%$ \\
Officer & $4,3 \%$ & $0,0 \%$ & $3,8 \%$ \\
Cattlemen & $5,4 \%$ & $7,1 \%$ & $5,7 \%$ \\
Others & $100,0 \%$ & $100,0 \%$ & $100,0 \%$ \\
Total & & & \\
\hline
\end{tabular}

(Source: primary data analyzed, 2018)

This is not surprising since Masakambing is a small island with many limitations. As revealed by Nurse et al. (2001), the characteristics of small islands as such Masakambing Island are closely related to vulnerability and insularity due to geographical limitations, natural resources, water resources, infrastructure and human resources.

Likewise, Masakambing Island community is dependent/influenced by external power, especially by the village government. Based on the descriptive analysis that resulted from 160 respondents, the highest norm adherence (answering at score 5) is on village governance norms is more dominant (33\%) compared to norms of social (28.8\%), custom (25.6\%), moral (29.4\%) 
and ethic (21.9\%). The high level of community norm adherence to the village government illustrates the effectiveness of services providing, one of them is controlled by the community income variable (Myeong \& Seo, 2016).

This result is supported by the fact that the community has a high dependency on the figure of the village head who is considered capable of facilitating and providing solutions to all problems. For example, when a person needs medical treatment, he will come to the village head to ask the guidance and help. Similarly, it was applied in terms of yellow-crested cockatoo. When the village government issued Village Regulation No. 1/2009 concerning protection of yellow-crested cockatoo and its habitat, the community obeys by not hunting and trading this animal. This result is consistent with Nandika, et al. (2019), the population of the yellow-crested cockatoo in Masakambing Island is increasing from 11 in 2010 into 13 in 2011.

"I obeyed what the village head said, now I do not catch cockatoo. if I did it, I would be punished".

(Interview: Key informant, 2018).

When the community gets information from the stranger, the community will clarify to the village head. It is concluded that the community is strongly influenced/controlled by higher groups or external (social) rule. In this case, the village head and its regulations. This finding is similar to Ross et al (1983)'s findings in Mexican is included as the fatalist category, which is indicated by low social class.

Theoretically, the fatalist community considers nature as mysterious and irregularly change, then vision and managing nature are not required because of useless (nature capricious). This happened to the Masakambing Island community in perceiving the yellow-crested cockatoo. Fatalists view life as a lottery that does not need to be managed (Steg \& Siever, 2000). This finding is in line with the data of conservation activities of community to the yellow-crested cockatoo, which is still a very low level either from planning, protecting, maintaining, or empowering.

Table 3. Conservation activities level of local community to the yellow-crested cockatoo

\begin{tabular}{|c|c|c|}
\hline Level & Quantity & Percentage (\%) \\
\hline Very low & 81 & $14,3 \%$ \\
\hline Low & 39 & $21,4 \%$ \\
\hline Middle & 33 & $21,4 \%$ \\
\hline Hight & 6 & $7,1 \%$ \\
\hline Very hight & 1 & $28,6 \%$ \\
\hline Total & 160 & $100,0 \%$ \\
\hline
\end{tabular}

Source: primary data analyzed, 2018

The yellow-crested cockatoo existence in the area has been considered as a normal phenomenon by community. Everything will work as usual because the most important is to work for fulfilling the needs.

"if cockatoo is nested in my tree, never mind. If cockatoo is extinct, it's okay. Because I keep working like this".

(Interview: Key informant, 2018) 
Although the community understood that catching is a violation, however, if they need the tree or the tree is considered disturbing, then they will cut it down. It is means the yellowcrested cockatoo is not a determinant factor in making decisions. Fatalist community has principle "getting what you can if you can", in accessing and exploiting natural resources (Halik et al., 2018).

\section{The perception based on advantages and disadvantages}

Basically, endangered species that live in the wild has an important role in the ecosystem balancing. But, it will be perceived differently by the community who coexist related to the advantages and disadvantages. At present, there are nine nested trees in which eight of those are located at the private ownership, and only one tree is at the mangrove area of state ownership. The community feels undisturbed for the existing of the yellow-crested cockatoo.

Table 4. The perception based on advantages and disadvantages aspect

\begin{tabular}{|c|c|c|c|}
\hline Advantages & Option & Disadvantages & Option \\
\hline The Existence is natural. & $\sqrt{ }$ & Damaging crops & $\sqrt{ }$ \\
\hline $\begin{array}{l}\text { Provide income benefits such as tourism } \\
\text { activities }\end{array}$ & $\sqrt{ }$ & $\begin{array}{l}\text { Spending the time (community keep the } \\
\text { crops) }\end{array}$ & \\
\hline The trigger of infrastructure development & $\sqrt{ }$ & Livestock predator & \\
\hline Required for culture or ritual & $x$ & $\begin{array}{l}\text { Reducing/ occupying land for the future } \\
\text { generation, crop cultivation and spring. }\end{array}$ & \\
\hline Serving food, medicine or entertainment & $x$ & Social instability (community fear) & \\
\hline \multicolumn{4}{|l|}{ Note: } \\
\hline$\sqrt{ }:$ Yes/ Occured & & & \\
\hline$\times \quad: \quad$ No/ Not occured & & & \\
\hline
\end{tabular}

(Source: Primary data analyzed, 2018)

The community assumes the yellow-crested cockatoo is beneficial as an incomegenerating from tourists visit to the region. The community realized, this animal made this region famous. It has been noted, two big groups of tourist visited the island which was initiated by KKI-IPP. In 2015 and 2018, more than ten people consisted of the journalist, bird watchers and hobbyists from any countries (Indonesia, America, Australia, Singapore, Canada and the Netherlands). Tourists becomes an income trigger for the community by providing services of boat, guest house, food, motorcycle and guide. It proved that this activity provides an economic impact to the community. Marsiglio (2015) stated, ecotourism could be a trigger for economic development by keeping environmental quality as long as it involves the community.

"foreign tourists have come to enjoy the cockatoo. The community was happy because we got money from guest house rental and motorcycle rental, village became glory and famous"

(Interview: Key informant, 2018)

On the other hand, the community feels proud of the existence of yellow-crested cockatoo because it had trigggered infrastructure development. The Indonesia Government through the Decree of the Directorate of forest protection and nature conservation (PHKA) No. 200 / IV / KKH / 2015 defined this animal as priority species for population improvement. This 
policy has put more attention on the Masakambing Island. The government is currently on the process of defining the status of Masakambing Island as an essential ecosystem area. Essential ecosystem area means a protected ecosystem area outside the Nature Reserve and/or Nature Conservation Area which has important values ecologically that support sustainability of biodiversity trough conservation activities for society welfare and improve human life quality. Beneficially, there are special budgets from the central and regional government and other parties. In addition, there are incentives related to environmental services, conservation assistance and prevention of pollution/ environmental damage and restoration. This is similar to the Latin America and Caribbean Region, conservation mainstreaming implements the development of various infrastructures such as roads, gas pipes, dams and water supply (Quintero, 2007).

The population od Masakambing Island are totally Moslem with no religious rituals utilizing this animal. There are no native persons at Masakambing Island, they are migrant from Sulawesi (Bugis and mandar ethnic) and East Java (Madura). Bugis and Mandar ethnic groups are familiar with this animal because there is yellow-crested cockatoo sub-species sulphurea in their ancestral land (Sulawesi). Similarly, there is no traditional rituals related to this animal. In contrast to west Malaysia, where Budhists perform ritual related to marine turtle (Northcott, 2012).

The community does not exploit the yellow-crested cockatoo for food or entertainment. In other places, animal exploitation (even though endangered species) for food or entertainment are common. There were $29.6 \%$ of respondents in Beijing, Shanghai, Guangzou, Kunning and Nanning China consume wild animal for food and traditional medicine (Zhang \& Yin, 2014). Meanwhile, Brando (2016) recognized wildlife species that are regularly found in entertainment are parrots, ibis, owls and eagle.

A small portion of the local community perceived a disadvantagous aspect, especially related to damaging crops of corn and coconut. A few people thought to drive out or expect for the extinction. Moreover, there is another perception that the yellow-crested cockatoo had damaged clove plant. It is an improper opinion since the clove plant is not categorized as feeding, nesting and sleeping tree for this animal.

"if there are cockatoo in my corn platation, I will drive out..."

(Interview: Key informant, 2018)

Corn attack was massive during 1980-1990 when the population of the animal was abundant. Then, the community invited cockatoo tamer from Nusa Tenggara to catch them. Conversely, it was acknowledged during that period the productivity of corn and coconut were high. This animal is an effective natural enemy against tree rat attacks on coconut. It is found, coconut trees being used for nesting, sleeping and feeding are free from tree rat attacks. Ultimately, the natural ecosystem in an area will be sustainable when native biodiversity and basic function of productivity are maintained (Marcot \& Heyden, 2016).

The yellow-crested cockatoo is not a predatory animal for livestock. Nandika et al (2012b) noted, some favoured foods are artocarpus communis, fruit and flowers of cocos nucifera, young leaves and flowers of ceiba petandra, mangroves, male flowers of brassus sudaica and at least six species of fruit, flowers and seeds. For nesting, this animal uses some trees with low economic value. Nandika, et al (2012a) have identified that cockatoos tend to use a chink in the trunk or branch, or a pre-existing nest-hole made by another species, often in dead, snagged or rotting trees such as $C$. nucifera, A. communis, C. petandra, Tamarindus indica and 
Avicennia sp. As the most important thing, this animal does not disturb the spring water in this region. The yellow-crested cockatoo utilizes coconut water for drinking and does not go down to the ground to drink or eat. In other words, the yellow-crested cockatoo is not reducing/occupying land for the future generation, crop cultivation and spring. This implies the existence of this animal is undisturbing for social stability. It is different from the animals that attack human, prey on livestock and crop have been perceived negative (Sifuna, 2010).

This animal coexists with the community; therefore, the preservation absolutely requires community involvement (community-based conservation or CBC). Spiteri \& Nepal (2006) stated, $\mathrm{CBC}$ is a conservation activity that empowers the community in managing conservation activities that aims to create accountability and grow a sense of belonging. The success of CBC has been proven by Lee's study (2018) about the increasing of giraffe population and the improving of its habitat management in Tanzania. Incentives for community involvement can be initiated by increasing the benefit value. It is in line with a statement of Nillson et al (2016), that the mechanism to increase community involvement for conservation can be implemented by providing alternative livelihoods both direct or indirect. In the case of the local community of Masakambing Island, the development of tourism activity based on the yellow- crested cockatoo attractions can be developed continuously.

\section{Conclusion}

The structure of the local community of Masakambing Island as a small island community has been closely related to vulnerability and insularity that has powerlessness and limited choices for livelihood activities. The community has a perception that there is no need to either manage or to have vision related to the yellow-crested small due to no impact. Although a few in the community perceive the yellow-crested cockatoo to damage corn and coconut plants, it is natural. On the other hand, the community also recognized that the existence of this animal provides income benefits through tourism activities and infrastructure development trigger.

\section{Acknowledgement}

We would like to thank the LPDP Ministry of Finance of the Republic of Indonesia for funding this study. Likewise, the village government of Masakambing, NRCA of East Java, Indonesia, KKI-IPP and PA Kawali who have provided a lot of facilitation and information for this study.

\section{References}

Abdullah, J., Ahmad, C.B., Jaafar, J., \& Sa'ad, S.RM. (2013). Stakeholder's perspective of criteria for delineation of buffer zone at conservation reserve: FRIM heritage site. Procedia - Social and Behavioral Sciences, 105(2013), 610-618

Bencin, H., Kioko, J., \& Kiffner, C. (2016). Local people's perceptions of wildlife species in two distinct landscapes of Northern Tanzania. Journal of Nature Conservation, 34, 82-92

Bennett, N.J., Roth, R., Klain, S. C., Chan, K., Christie, P.C., Douglas, A., Cullman, G., Curran, D., Durbini, T. J., Epstein, G., Greenberg, A., Nelson, M.P., Sandlos, J., Stedman, R., Teel, T.L., Thomas, R., Veríssimo, D., \& Wyborn, C. (2017). Conservation social 
science: Understanding and integrating human dimensions to improve conservation. Biological Conservation, 205(2017), 93-108.

Billgren, C. \& Holmen, H. (2008). Approaching reality: Comparing stakeholder analysis and cultural theory in the context of natural resource management. Land Use Policy, 25(2008) $550-562$.

Brando, S. (2016). Animal Ethics in the Age of Humans in B. Bovenkerk and J. Keulartz (eds.), Wild Animals in Entertainment., The International Library of Environmental, Agricultural and Food Ethics 23, DOI 10.1007/978-3-319-44206-8_18

Bredin, Y. K., Linnell, J. D.C., Silveira, L. Tôrres, N.M., Jácomo, A. A., \& Swenson, J.E. (2015). Institutional stakeholders' views on jaguar conservation issues in central Brazil. Global Ecology and Conservation, 3(2015), 814-823

Castelletta, M., Thiollay, J-M., \& Sodhi, N.S. (2005). The effects of extreme forest fragmentation on the bird community of Singapore Island. Biological conservation, 121 (2005), 135-155

Clark, V., Plano., \& Creswell, J.W. (2015). Understanding research a consumer guide. New Jersey, Pearson.

Collar N. J., \& Marsden, S. J. (2014). The subspecies of yellow-crested cockatoo cacatua sulphurea. Forktail, 30(2014), 23-27.

Daltona, T.J., Yahayaa, I., \& Naab, J. (2014). Perceptions and performance of conservation agriculture practices innorthwestern Ghana. Agriculture, Ecosystems and Environment, 187(2014), 65-71.

de Snoo, G. R., Herzon, I., Staats, H., Burton, R.J.F., Schindler, S., van Dijk, J., Lokhorst, A.M., Bullock, J.M., Lobley, M., Wrbka, T., Schwarz, G., \& Musters, C.J.M. (2013). Toward effective nature conservation on farmland:making farmers matter. Conserv. Lett., 6, 6672.

Douglas, M. (1970). Natural symbols: explorations in cosmology. London, Barrie and Rockliff.

Douglas, M., Wildavsky, A. (1982). Risk and culture: an essay on the selection of technical and environmental danger. University of California Press, Berkeley.

Friedrich, L.A., Jefferson, R., Glegg, G. (2014). Public perceptions of sharks: gathering support for shark conservation. Marine Policy, 47(2014), 1-7.

Gore, M.L., Kahler, J.S. (2012). Gendered risk perceptions associated with human-wildlife conflict: implications for participatory conservation. PLOS ONE 7

Gyawali, D., \& Dixit, A . (2001). Water and science: hydrological uncertainties, developmental aspirations and uningrained scientific culture. Futures, 33(2001), 689-708.

Halik, A., Verweij, M \& Schlüter, A. (2018). How marine protected areas are governed: a cultural theory perspective. Sustainability, 2018, 10, 252; doi:10.3390/su10010252.

IUCN Redlist. (2017). Cacatua Sulphurea. Retrieved from www.iucnredlist.org.

Jaafar, M., Noor, S.Md., Rasoolimanesh, S., Mostafa. (2015). Perception of young local residents toward sustainable conservation programmes: a case study of the Lenggong World Cultural Heritage Site. Tourism Management, 48(2015), 154-163.

Kanagavel, A., Parvathy, S., Nameer, P.Q., \& Raghavan, R. (2016). Conservation implications of wildlife utilization by indigenous communities in the southern Western Ghats of India. Journal of Asia-Pacific Biodiversity, 9(2016), 271-279.

Lee, D.E. (2018). Evaluating conservation effectiveness in a Tanzanian community wildlife management area. The journal of wildlife management, 2018; DOI: 10.1002/jwmg.21549 
Lestera, S.E., Ruffb., Elizabeth O., Mayallc, K., \& McHenry, J. (2017). Exploring stakeholder perceptions of marine management in Bermuda. Marine Policy, 84(2017), 235-243.

Marcot, B.G., \& Heyden, M.V. (2016). Key ecological functions of wildlife species. Chapter 6: Ecological Functions. In: Wildlife-Habitat Relationships in Washington and Oregon Retrieved from http://www.spiritone.com/ brucem/kef1.htm.

Marsiglio, S. (2015). Economic growth and environment: tourism as a trigger for green growth. Tourism Economics, 21(1), 183-204 doi: 10.5367/te.2014.041.

Marten, G.G. (2011). Human ecology basic concept for sustuinable development. London, Sterling.

Myeong., \& Seo, H. (2016). Which Type of social capital matters for building trust in government? looking for a new type of social capital in the governance era. Sustainability, 8, 322; doi:10.3390/su8040322.

Nandika, D. Agustina, D., Mertz MD, S., \& Zimmermann, B. (2012a). Study population and conservation lesser sulphur - crested cockatoo Caccatua sulphurea. Report Program 2005-2012. Konservasi Kakatua Indonesia - The Indonesian Parrot Project, Bekasi Indonesia.

Nandika, D., Agustina, D., \& Mertz MD, S. (2012b). Lesser sulphur-crested cockatoo, abbotti subspecies on Masakambing Island, East Java, Indonesia. Cyanopsitta September 2012.

Nandika, D., Mulyani, Y.A. Prawiradilaga, D.M., Agustina, D. (2019). A decade monitoring of the population of critically endangered Cacatua sulphurea abbotti In Masakambing Island, Indonesia. Biotrop (article in press).

Nilsson, D., Baxter, G., Butler, J.R.A., \& McAlpine, C.A. (2016). How do community-based conservation programs in developing countries change human behaviour? A realist synthesis. Biological Conservation, 200(2016), 93-103.

Northcott, M. (2012). Buddhist rituals, mosque sermons, and marine turtle: religion, ecology, and the conservastion of a dinosaur in West Malaysia. JSRNC 6.2 (2012), 196-214.

Novelli, M., Barnes, J.I., \& Humavindu, M. (2006). The other side of the ecotourism coin: consumptive tourism in Southern Africa. Journal of Ecotourism, 5:1-2, 62-79, DOI: 10.1080/14724040608668447.

Nurse, L. A., Sem, G., hay, J.E., Suarez, A.G, Wong, P.P., Briguglio, L., \& Ragoonaden, S. (2001). Small island states. Climate change, 843-875.

Prijono, Siti Nurmaliati. (2008). Case Study: Cacatua Sulphurea. Paper. NDF Workshop Case Studies $W G-6$

Quintero, J.D. (2007). Mainstreaming conservation in infrastructure projects case studies from latin america. Washington, D.C. U.S.A, The International Bank for Reconstruction and Development - The World Bank.

Rist, S., Chidambaranathan, M., Escobar, C., Wiesmann, U., Zimmermann, A. (2006). Moving from sustainable management to sustainable governance of natural resources: the role of social learning processes in rural India, Bolivia and Mali. Journal of Rural Studies, 23, $23-37$

Riveraa, A., Gelcichb, S., García-Flórezc, L., \& Acuñaa, J.L (2017). Heterogeneous management and conservation perceptions within the gooseneck barnacle co-management system in Asturias (N. Spain). Marine Policy, 81(2017), 229-235.

Rolling, N.G., Jiggins, J. (1997). The ecological knowledge system. In. Roling, N.G., Wagemakers, M.A. (Eds.), Social Learning for Sustainable Agriculture. Cambridge, Cambridge University Press. 
Ross, C. E., Mirowsky, J., \& Coekerham, W.C. (1983). Social class, mexican culture, and fatalism: their effects on psychological distress. American Journal of Community Psychology, 11(4).

Rowley I., Sharp, C.J., Boesman. P.( 2018). Yellow-crested Cockatoo (Cacatua sulphurea). In. del Hoyo J., Elliot, A., Sargatal, J., Christie, D.A., Juana.E, (eds.) IHandbook of the Birds of the World Alive. Lynx Edicions, Barcelona

Rowley, I., Sharpe, CJ., \& Boesman, P. (2018). Yellow-crested cockatoo (Cacatua sulphurea). In. del Hoyo, J., Elliot, A., Sargatal, J., Christie, D.A., Juana. E (Eds.), Handbook of the birds of the world alive. Barcelona, Lynx Edicions.

Sainsbury, K., Burgess, N.D., Sabuni, F.. Howe, C.. Puis, E., Killenga, R., \& Milner-Gulland, E.J. (2015). Exploring stakeholder perceptions of conservation outcomes from alternative income generating activities in Tanzanian villages adjacent to Eastern Arc Mountain forests. Biological Conservation, 191(2015), 20-28.

Sifuna, N. (2010). Wildlife damage and its Impact on public attitudes towards conservation: a comparative study of Kenya and Botswana, with particular reference to Kenya's Laikipia region and Botswana's. Journal of Asian and African Studies, 45(3), 274-296.

Spiteri, A., \& Nepal, S.K. (2006). Incentive-based conservation programs in developing countries: a review of some key issues and suggestions for improvements. Environmental Management, 37(1), 1-14. http://doi.org/10.1007/s00267-004-0311-7

Steg, L., \& Sievers, I. (2000). Cultural theory and individual perceptions of environmental risks. Environment And Behavior, 32(2), 250-269.

Taruvinga., \& Mushunje. (2014). Society`s perceptions of African elephants and their relativeninfluence towards the conservation of elephants. APCBEE Procedia 10 (2014), 299-304.

Thaman, B., Icely, J.D., Fragoso, B.D.D., Veitayak, J. (2016). A comparison of rural community perceptions and involvement in conservation between the Fiji Islands and Southwestern Portugal. Ocean \& Coastal Management, 133(2016), 43-52.

Thompson, M. (1997). Cultural Theory and integrated assessment. Environmental Modeling and Assessment, 2(1997), 139-150

Thompson, M., Ellis, R., Wildavsky, A. (1990). Cultural Theory. Boulder, CO, USA, Westview Press.

Thompson, T.L., \& Mintzes, J.J. (2002). Cognitive structure and the affective domain: on knowing and feeling in biology. Int J Sci Educ,24(6), 645-60.

Trainor, C. (2002). A Preliminary list of Important Bird Areas in East Timor: Interm list of priority sites for biodiversity conservation in Asia's newest country. BirdLife International - Asia Programme.

Twyman, C. (2001). Entitled to a living: opportunity and diversity in the Kalahari wildlife management areas. In, Sporton, D, \& Thomas, D.S.G. (eds.) Sustainable livelihoods in marginal African environments. Oxford, Oxford University Press.

Wearing, S., \& Neil, J. (1999). Ecotourism: impacts, and possibilities. Oxford, ButterworthHeinemann

Zegeye, H. (2016). In situ and ex situ conservation: complementary approaches for maintaining biodiversity. International Journal of Research in Environmental Studies. 4(2017): 1-12

Zhang, L., \& Yin, F. (2014). Wildlife consumption and conservation awareness in China: a long way to go. Biodivers Conserv. DOI 10.1007/s10531-014-0708-4 